\title{
Improving the balance of sheep and beef cattle livestock systems
}

AgResearch, Whatawhata Research Centre, Private Bag 3089, Hamilton

\begin{abstract}
Two data sets were used to analyse the impact of changes in stock policy from a dominant breeding ewe system to a dominant beef cattle finishing system. These included data from a farmlet trial and data from a monitored study farm. The Stockpol model was used to carry out the analyses. Required daily pasture demand and average minimum pasture covers increased as cattle finishing increased. Stock numbers had to be reduced for the policies to become biologically feasible, that is, for the increased pasture demands and pasture covers to be attainable on the farm. Historic stocking rate was not a good guide to the reduced stocking rate required. Tests of biological feasibility should be carried out before a change in policy can be analysed for its financial merits.
\end{abstract}

K eywords: biological feasibility, finishing, pasture cover, pasture demand, stock policy, systems

\section{Introduction}

The decline in sheep profitability during the late 1980s and early 1990s has seen marked reductions in sheep numbers, more particularly in the northern regions of New Zealand. In the years 1990 and 1991 alone, sheep numbers in Northland dropped by 15\% (Agriculture Statistics 1990 and 1991). On traditional sheep and beef cattle farms, breeding ewes were predominantly replaced by finishing cattle (bulls, heifers and steers). However, these livestock policy changes were made without adequate prediction of the changes in seasonal feed demand patterns, base pasture covers, or feed quality that were likely to occur. Moves toward apparent financial gain were not necessarily successful. The decision-making process must first answer the question, "will changes in stock policy work in practice?" Only then can these changes be financially evaluated.
Farm monitoring studies in Northland (Webby \& Sheath 1991) highlighted the predicament farmers can experience when changing stock policy. This paper reports the analysis carried out to understand the consequences that changes in livestock policy have on a total farm system, and the impact of stock policy changes on a Northland study farm.

\section{M ethods}

\section{Database}

Two data sets are involved. 1) Data from a farmlet grazing trial on the Whatawhata Research Centre (Webby et al. 1990). 2) Data from a study farm in the Northland farm monitoring programme (Webby et al. 1991). Information contained in each data set included monthly pasture growth measurements, quarterly farm cover measurements, stock liveweights, weight gains, numbers, and records of sales and purchases.

The farmlet stock policy involved breeding ewes and Friesian bulls brought in at the end of November and sold at the end of January, 14 months later. All lambs were sold by mid February and replacements brought in as two-tooth ewes in January. The liveweight gains for the Friesian bulls are illustrated in Table 1. There were $129 \%$ lambs weaned to ewes mated and at weaning the average lamb weight was $19.0 \mathrm{~kg}$. This was the performance achieved from a 70:30 sheep to cattle ratio at 14 su/ha.

The pattern of stock policy change on the Northland study farm is illustrated in Table 2. Numbers of animals in each stock class carried on 1 July each year are shown. The stock unit values used were, for ewes 1 , hoggets 0.8 , cows 6 , dry rising 2-year heifers ( 2 yr hfr) 5, rising 1-year heifers ( $\mathrm{R} 1 \mathrm{yr} h f r) 4$, rising 1-year steers (R 1 yr str) 4.5, rising 2-year steers (R 2 yr str) 6, rising 3-year steers (R 3 yr str) 6, rising l-year bulls 5 and breeding bulls 6 . The sheep to cattle ratios are calculated using these stock units.

Table 1 Average liveweight gain ( $\mathrm{kg} / \mathrm{day})$ for bulls in the farmlet trial,

\begin{tabular}{lccccccccccccc}
\hline Month & Jul & Aug & Sep & Oct & Nov & Dec & Jan & Feb & Mar & Apr & May & Jun \\
\hline R yr bulls & 0.7 & 1.0 & 1.2 & 1.2 & 1.0 & 0.9 & 0.5 & . & . & , & - & \\
Calves & & & & & 0.7 & $\mathbf{0 . 7}$ & 0.5 & 0.4 & 0.3 & 0.3 & 0.7 & 0.7 \\
\hline
\end{tabular}


Table 2 The patterns of changing stock policy illustrated by changes in stock numbers from a Northland monitor farm.

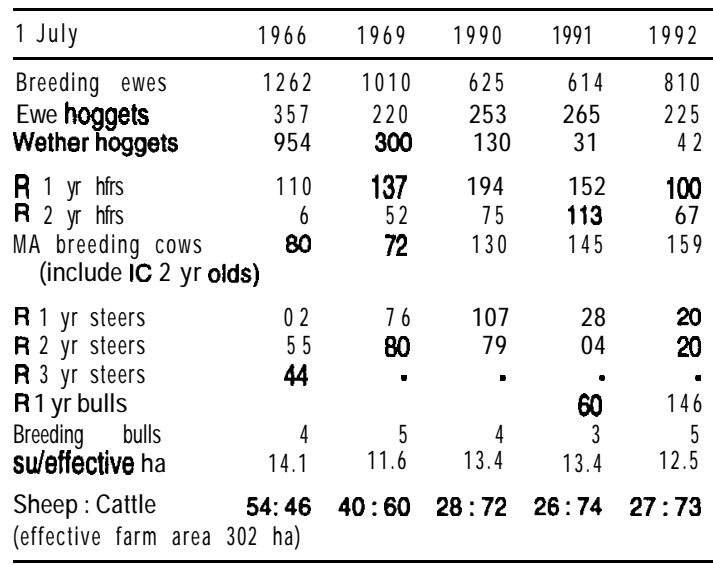

The liveweight gain targets that were set, and the levels achieved for R $1 \mathrm{yr}$ hfrs, R 1 yr strs and bulls calves for 1990/91, are in Table 3 . There were $121 \%$ lambs weaned to ewes mated and lambs weaned at 14 weeks averaged $22.5 \mathrm{~kg}$ in that year.

The principal tool used in the analyses was the Stockpol model (Marshall 1991). The model handles animal intake and pasture residual as described by McCall (1986). It also includes the dynamics of pasture growth using pasture mass as functions of pasture growth and decay (Bircham 1984). In these analyses, the feed requirements (as pasture) of livestock to achieve maintenance of liveweight plus liveweight gain, is expressed as pasture demand $(\mathrm{kg} \mathrm{DM} / \mathrm{ha} /$ day) (Figures 1 and 4). The minimum pasture covers required to achieve the levels of livestock performance actually gained are expressed as monthly average $\mathrm{kg} / \mathrm{DM} / \mathrm{ha}$ (Figures 2 and 5).

Analyses

For the farmlet trial data simulated runs were made using the model and adjusting the sheep to cattle ratio to $100: 0,50: 50,30: 70$ and $0: 100$ at a constant 14 su/ha. The results at 70:30 were base runs on the actual data, the model being used to calculate monthly daily pasture demand and minimum pasture cover.

The data from the Northland monitor farm were used to calculate the monthly daily pasture demand and pasture covers through three key years of the policy changes: $1988 / 89,1990 / 91$ and 1991/92 (Figures 4 and 5). Also calculated for $1990 / 91$ were the required pasture demand and covers for the liveweight gain targets set by the farmer (Table 3).
Table 3 Actual and target liveweight gains ( $\mathrm{kg} / \mathrm{day}$ ) for finishing cattle on the Northland study farm $1990 /$ 91.

\begin{tabular}{|c|c|c|c|c|c|c|}
\hline \multirow[b]{2}{*}{ Month } & \multicolumn{2}{|c|}{ Bull calves } & \multicolumn{2}{|c|}{ A $1 \mathrm{yr}$ hrrs } & \multicolumn{2}{|c|}{ A1 yr strs } \\
\hline & Actual & Target & Actual & Target & Actual & Taroet \\
\hline July & & & 0.4 & 0.7 & 0.8 & 0.7 \\
\hline Aug & & & 0.6 & 0.7 & 0.0 & 0.7 \\
\hline Sep & & & 0.9 & 0.7 & 0.0 & 0.0 \\
\hline Oct & & & 0.9 & 0.9 & 1.0 & 1.0 \\
\hline NW & 0.7 & 0.7 & 1.0 & 1.0 & 1.2 & 1.2 \\
\hline Dec & 0.7 & 0.7 & 0.8 & 0.8 & 1.2 & 1.2 \\
\hline Jan & 0.5 & 0.5 & 0.6 & 0.6 & 0.5 & 0.8 \\
\hline Feb & 0.5 & 0.5 & 0.2 & 0.5 & 0.3 & 0.5 \\
\hline Mar & 0.6 & 0.6 & 0.2 & 0.4 & 0.2 & 0.4 \\
\hline Apr & 0.7 & 0.7 & 0.2 & 0.4 & 0 & 0.4 \\
\hline May & 0.6 & 0.7 & 0.2 & 0.7 & 0 & 0.7 \\
\hline Jun & 0.5 & 0.7 & 0.1 & 0.7 & 0 & 0.7 \\
\hline
\end{tabular}

Figure 1 Changes in daily pasture demand with changes in the ratios of breeding ewes to 20 -month Friesian bulls ( $\mathrm{kg}$ DM/ha/day).

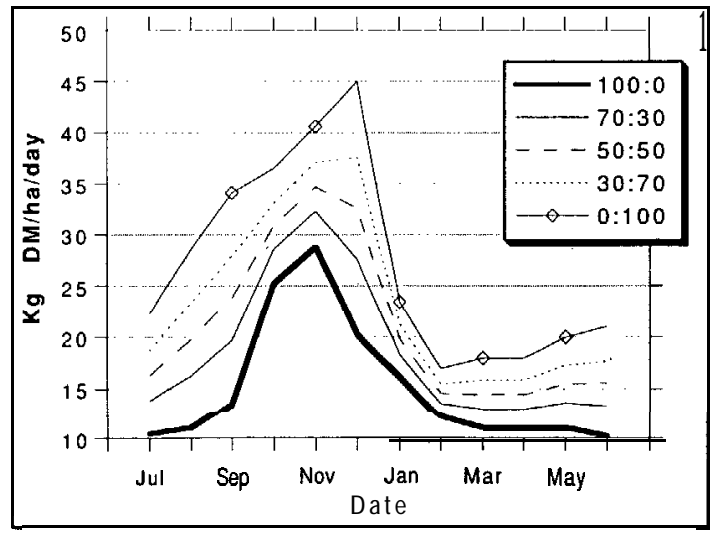

Figure 2 Minimum pasture cover requirements for changes in ratios of breeding ewes to 20-month Friesian bulls ( $\mathrm{kg}$ DM/ha).

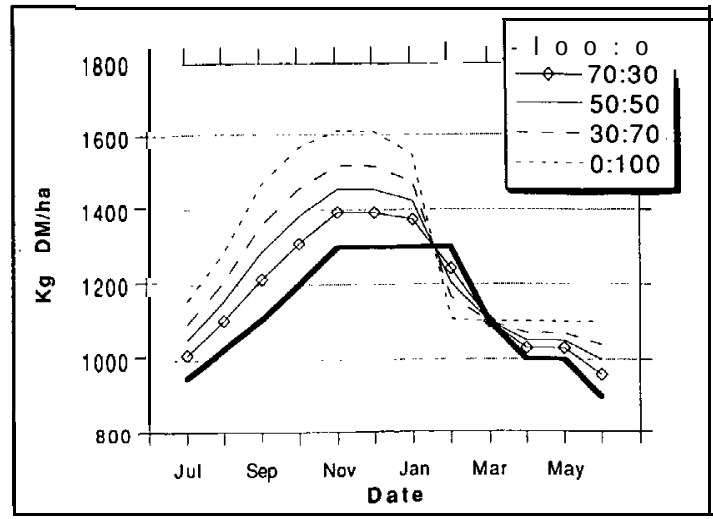




\section{Results and discussion}

\section{Farmlet trial}

The monthly daily pasture demands for each of the sheep to cattle ratios are in Figure 1. Stocking rate was unchanged but daily pasture demand increased as the ratio of cattle increased. The average monthly pasture covers are in Figure 2. Increased pasture covers are required from July through until January with increased cattle ratios. The sudden drop in pasture cover requirements from January to February was due to the sale of the 18-month-old Friesian bulls from the system. This left only bull calves that had joined the system at the end of November. Covers remained high in the sheep system through February while lambs were retained.

For the increased cattle policies to be biologically feasible, decreases in stock numbers were made within the model until pasture covers and monthly daily pasture demand matched attainable pasture covers and pasture supply. Figure 3 shows the feasible stocking rates as stock units per ha. The sheep-only policy allowed an increase in stocking rate over the base $70: 30$ policy by $11 \%$, i.e., from 10 ewes and 1 bull/ha to 15.6 ewes/ha, whereas the all-cattle policy dropped from an all-sheep equivalent of $15.6 \mathrm{su} / \mathrm{ha}$ to an all-bull equivalent of 11.9 su/ha, a reduction of $24 \%$ in stocking rate, i.e., from 3.3 bulls/ha to 2.5 bulls/ha.

The higher pasture covers required under the cattledominated system reduced pasture utilisation, making the system biologically less efficient than a system at a higher stocking rate. This analysis has taken into account the increased pasture demand and increased pasture cover requirements of the cattle-dominated policy. The reduction in stocking rate of $24 \%$ from all sheep to all cattle may still be insufficient when likely changes occur in pasture composition under all-cattle grazing (Monteath 1977).

\section{Northland study farm}

The stock policy changes that occurred on this farm (Table 2) were made by the farmer because of a discontent with sheep (increasing animal health problems particularly flystrike and facial eczema) and to improved financial returns from cattle.

The key features of the stock policies each year were:

1. In 1988, 954 male hoggets were carried through into late winter and $44 \mathrm{R} 3 \mathrm{yr}$ strs were present on the farm.

2. In 1989 ewe numbers were down 250 from the previous year, breeding cows down 8 , finishing cattle numbers were up by 46 , and 300 male hoggets
Figure 3 Changes in stocking rate required to make changes in stock policy biologically feasible (breeding ewes and 20-month Friesian bulls).

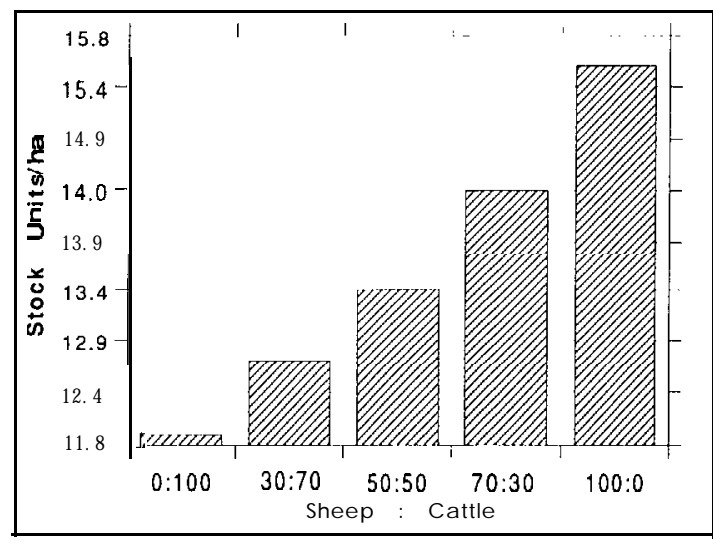

Figure 4 Actual pasture demand (kg DM/ha/day) for the 1988/ $89,1990 / 91$ and 199 1/92 stock policies, and the pasture demand requirements to achieve the target liveweight gains for 1990/91 - Northland study farm.

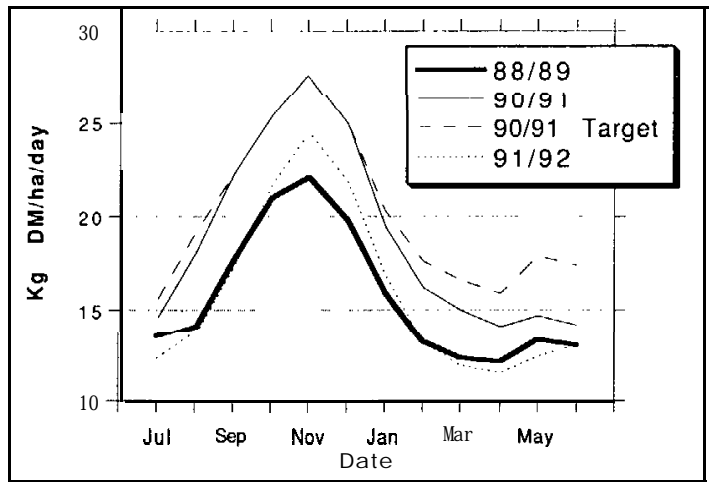

Figure 5 Actual minimum pasture cover ( $\mathrm{kg}$ DM/ha) requirements for the 1988/89, 1990191 and 1991/92 stock policies, and the minimum pasture cover required to achieve the target liveweight gains for 1990/91 Northland study farm.

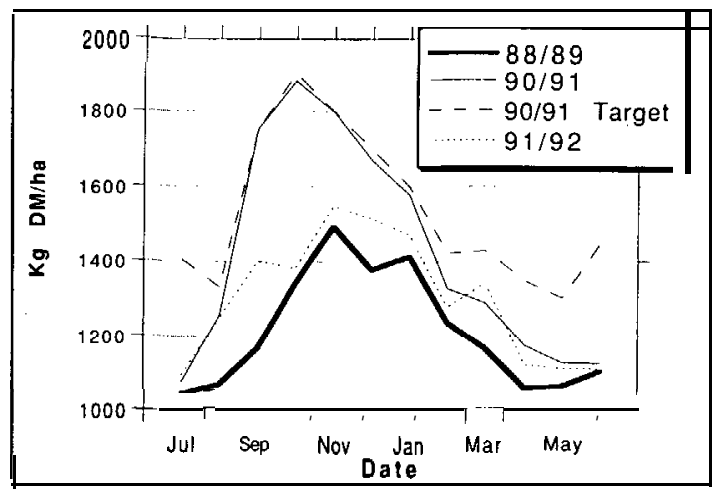


were carried through into late winter.

3. In 1990, breeding ewes dropped by a further 185 but cow numbers were up by 58 .

4. In 1991, ewe numbers stabilised, cow numbers still increased, and for the first time rising l-year bulls were introduced into the system.

5. In 1992, heifer and steer finishing numbers decreased, cow numbers increased and bull numbers increased to 146 .

Pasture demand profiles and minimum pasture covers for the performance achieved in 1988/89, 1990/ 91 and 1991/92, alongside the target levels required for 1990/9 1, are illustrated in Figures 4 and 5.

Although the target ratio of $\mathbf{2 8 : 7 2}$ sheep to cattle was reached in 1990 the changes in stock policy from then on were essentially the transition towards a workable and profitable livestock system. The 1990/91 policy was clearly carrying an excessive number of stock through into the 1991/92 year. The high actual minimum pasture covers of the spring 1990 (refer Figure 5) reflect the needs of 301 1-year cattle in the system at that time. In July $1991110 \mathrm{R} 2 \mathrm{yr}$ hfrs were sold, reducing the daily pasture demand by $2 \mathrm{~kg} \mathrm{DM} / \mathrm{h} a /$ day (Figure 4). The policy objective to achieve the sale of finishing cattle before their second winter is reflected by further reductions in $\mathrm{R} 2 \mathrm{yr}$ cattle present on 1 July 1992. The bull policy provided more market flexibility with sale on liveweight alone compared with liveweight and condition for prime stock (steers and heifers).

The analyses reflect the dynamics of a commercial farming operation and the potential for stock policies to become unworkable. High pre-winter pasture covers were required for a high performing cattle system. Attempts by the farmer to maintain the base year stocking rate of 14.1 stock units/ha were not possible. Liveweight targets in 1990/91 were not achieved even at the lower stocking rate of 13.4 stock units/ha (refer Table 2). By 1 July 1992 the stocking rate was down to $12.5 \mathrm{su} / \mathrm{ha}$. The successful outcome of any stock policy will depend on the achievement of both livestock performance targets and target sale dates.

The transition from sheep to cattle in this study farm example was initially a reduction in breeding ewes followed by an increase in breeding cows. This put the farmer in an improved position for the maintenance of feed quality, a necessary prerequisite for the growing of young stock in that environment.

A farmer's objective when moving towards higher demanding cattle systems must be to improve the supply of feed into the system. Reducing stock numbers may be the first consideration, but alternatives such as improving pasture production (e.g., with nitrogen) or adding supplements (e.g., forage crop) must also be considered.

\section{Summary}

This study has emphasised:

1. The need to first test the biological feasibility of any proposed change in stock policy. This test will then provide the stock numbers to use in a financial evaluation of the policy.

2. Increased finishing cattle means an increase in autumn, winter and early spring pasture demand and the minimum pasture covers required.

3. To maintain higher levels of pasture cover and pasture demand, either stock numbers have to be reduced, or more feed added into the system.

4. Higher pasture covers mean increasing pasture quality constraints. Successful beef cattle finishing systems include stock policies that can manage the constraints of pasture quality.

\section{R E F E R E N C E S}

Bircham, J.S.; Korte, C.J. 1984. Principles of herbage production. Proceedings of the NZIAS Convention 18(13): 123-126.

Marshall, P.R.; McCall, D.G.; Johns, K.L. 1991. Stockpol: A decision support model for livestock farms. Proceedings of the New Zealand Grassland Association 53: 137-140.

McCall, D.G.; Townsley, R.J.; Bircham, J.A. 1986. The interdependence of animal intake pre- and postgrazing pasture mass and stocking density. Proceedings of the New Zealand Grassland Association 53: 13- 16.

Monteath, M.A.; Johnstone, P.D.; Boswell, C.C. 1977. Effects of animals on pasture production. New Zealand journal of agricultural research 20: 2330.

Webby, R.W.; Sheath, G.W.; Boom, C.J. 1990. Performance of new pasture cultivars in a hill country finishing system. Proceedings of rhe New Zealand Grassland Association 51: 151-156.

Webby, R.W.; Sheath, G.W. 1991. Group monitoring, a basis for decision making and technology transfer on sheep and beef farms. Proceedings of the New Zealand Grassland Association 53: 13- 16. 